\title{
O LEITOR-LITERÁRIO ENTRE OS MUROS DA ESCOLARIZAÇÃO: ANÁLISE DA (IN) VISIBILIDADE DA LITERATURA INFANTIL NA BNCC ${ }^{1}$
}

\author{
THE LITERARY READER AMONG SCHOOLING WALLS: \\ ANALYSIS OF CHILD LITERATURE (IN) VISIBILITY
}

\author{
Camila Rodrigues Viana ${ }^{2}$ \\ Janete Silva dos Santos ${ }^{3}$
}

\begin{abstract}
Resumo: Esta pesquisa aborda a Literatura Infantil a partir de um diálogo entre a leitura escolarizada e os critérios pedagógicos da Base Nacional Comum Curricular (BNCC). Trilhase, uma análise que protagoniza o leitor-literário infantil e o lugar da literatura no documento em pauta. Com efeito, contribui-se com noções reflexivas de as escolhas literárias devem levar em consideração um leitor infantil em formação, com aspectos cognitivos e psicossociais típicos de cada idade ou etapa de ensino, (não) possuidor de repertórios literários e imbricado de suas práticas sociais.
\end{abstract}

Palavras-chaves: literatura infantil; escolarização; BNCC.

Abstract: This research approaches the Children's Literature from a dialogue between the schooled reading and the pedagogical criteria of the Common National Curricular Base (BNCC). Trilha, an analysis that protagonizes the child literary reader and the place of the document literatur. Indeed, it contributes with reflective notions that literary choices should take into consideration a child reader in formation, with cognitive and psychosocial aspects typical of each age or stage of education, (not) possessing literary repertoires and intertwined with their social practices.

Keywords: children's literature; schooling; BNCC.

\section{Introdução}

Atualmente, um dos assuntos mais discutidos na educação se refere à produção e implementação da Base Nacional Comum Curricular (BNCC) $)^{4}$ nos currículos da educação

\footnotetext{
${ }^{1}$ Artigo fruto da disciplina Mulheres formadoras de leitores: crítica, autoria e ensino, ministrada no PPGL, UFT, campus Araguaína, pela professora Dra. Ana Crélia Penha Dias, docente da UFRJ.

${ }^{2}$ Doutoranda do Programa de Pós-Graduação em Letras: ensino de Línguas e Literatura (PPGL) da Universidade Federal do Tocantins (UFT). Docente da Universidade Federal do Maranhão (UFMA). Mestra em Letras (UFT). Graduada em Letras Língua Portuguesa /Inglesa e suas respectivas literaturas (UEMA) e Pedagogia (UFMA). E-mail: camila.rodrigues@ufma.br

${ }^{3}$ Doutora e mestre em Linguística Aplicada pela Unicamp, licenciada plena em Letras pela UFPA. Docente (adjunto IV) da universidade Federal do Tocantins (UFT) no curso de Letras (graduação) e no Programa de Pósgraduação em Letras (PPGL). E-mail: janetesantos@mail.uft.edu.br

${ }^{4}$ Um documento que se torna uma exigência colocada para o sistema educacional brasileiro pela Lei de Diretrizes e Bases da Educação Nacional (BRASIL, 1996; 2013), pelas Diretrizes Curriculares Nacionais Gerais da Educação Básica (BRASIL, 2009) e pelo Plano Nacional de Educação (BRASIL, 2014), e "deve se constituir como um avanço na qualidade da educação" (BRASIL, 2016, p. 24).
} 
infantil, fundamental e médio. Tal repercussão ganhou amplitude em 2016, pós divulgação da $1^{\text {a }}$ versão, intensificada após sua homologação em 2018, versão final, por (re)configurar os paradigmas nas Políticas Públicas voltadas para a Educação Básica. Por esse viés, tem-se, especificamente as mudanças, com avanços e limitações, nos critérios pedagógicos direcionados para a mediação do Livro Literário (doravante LT), visto aqui como livros de leitura, especialmente as recomendações voltadas para os anos iniciais do ensino fundamental, foco da pesquisa.

Um dos objetivos da Base é garantir o direito de aprendizagem desde a infância, definir conjunto de aprendizagens essenciais, competências e habilidades, especificamente em cada etapa de ensino e nortear as práticas pedagógicas. Com a promulgação da base, são notórias tensões e conflitos tanto de cunho teórico, científico, como pedagógico, em todo o país, especialmente as questões ligadas à Língua (gem), o ensino de Literatura e Língua Portuguesa. Umas das maiores polêmicas na área de linguagens são: o uso da semiótica ${ }^{5}$, desde a educação infantil, a antecipação da alfabetização e unificação curricular, dentro de um país desigual em todos as esferas.

Já as mudanças mais explícitas apresentadas pelo documento estão na ênfase no ensino da Literatura, considerando-se o pressuposto de que "o texto é uma prática social, tornando-se a centralidade no processo de formação dos sujeitos" (BRASIL, 2016, p. 92), bem como recomenda para cada etapa, "um leque de gêneros literários adequados aos leitores em formação”. (BRASIL 2016, p. 96. Para tanto, enfatiza-se, nesta investigação, a formação do leitor infantil e a leitura escolarizada a partir das recomendações da BNCC, os critérios avaliativos e pedagógicos. Com efeito, analisa-se como a Literatura Infantil se consolida enquanto prática educativa, ou seja, o uso de LT como parte do processo de escolarização da criança. Então, precisamos compreender que as escolhas literárias devem levar em consideração um leitor infantil em formação, com aspectos cognitivos e psicossociais típicos de cada idade ou etapa de ensino, (não) possuidor de repertórios literários e imbricado de suas práticas sociais.

\section{A literatura infantil entre os muros da escolarização}

O livro traz o conhecimento do mundo, do homem, das coisas, da natureza, do progresso das ciências e das técnicas. Os livros

\footnotetext{
${ }^{5}$ Termo especializado da área de linguística e recomendado pela base, desconsiderando a formação inicial de quem pode ensinar Literatura e Língua Portuguesa, ou seja, a educação infantil e os anos iniciais, de modo geral, têm o profissional da pedagogia, o pedagogo, como atuante e responsável por estas etapas de ensino.
} 
podem dizer, auxiliam na aprendizagem do mundo. (GÓES, 2010, p.27)

Contar, ler, ouvir, falar são competências linguísticas imersas no universo mágico da literatura infantil, em que as histórias se transformam em representações afetivas, simbólicas e conforme as concepções de Lajolo (1982, p. 29) "a presença da literatura na escola pode contribuir decisivamente para a formação de um público leitor". Assim, o processo de escolarização da criança deve ir muito além dos recursos estéticos da linguagem e a compreensão e a interpretação textual não podem ser unívocas.

Por esse viés, Soares (1999, p. 23-24) assegura que a apropriação da Literatura Infantil pela escola acontece em três instâncias: "a biblioteca escolar; a leitura e estudo de livros de literatura, em geral determinada e orientada por professores de Português; a leitura e o estudo de textos, em geral componente básico de aulas de Português". Candido (2002) complementa que a literatura possui três funções: a psicológica, a formadora e a social.

Constamos, desse modo, que a formação do leitor infantil ocorre, geralmente, nas aulas de Língua Portuguesa, mas que é importante um ambiente alfabetizador na qual a criança tem acesso aos livros, as leituras. Espaços como cantinho da leitura ou biblioteca escolar são criados para fornecer momentos específicos de leituras, individuais ou coletivas. Vale pontuar, que dilemas são levantados nos espaços de leituras, visto que de um lado temos uma motivação de acesso a leituras, com diversidade de gêneros, histórias, e fantasias e de outro a leitura por obrigação, escolhida pelo mediador e com caráter avaliativo.

Dessa forma, "não há como se ter escola sem ter escolarização de conhecimentos, saberes, artes" e os saberes escolares "formalizam em currículos, matérias e disciplinas, programas, metodologias". (SOARES, 2001, p. 20). A escola é a instância com espaço de ensino e de um tempo de aprendizagem e ao se atribuir uma atividade educativa à literatura infantil, complementar a atividade pedagógica exercida no lar, a leitura passa a ter um papel fundamental o tripé da formação social, psicológica e cognitiva da criança. (COLOMER, 2003). Com efeito, para comtemplar esse tripé é preciso que o processo de escolarização trilhe

uma pedagogia da leitura que objetiva a transformação do leitor e, através deste, da
sociedade, dificilmente se funda na descrição da estrutura dos textos. Mais do que
isso, uma pedagogia da leitura de cunho transformador propõe, ensina e encaminha
num sistema comunicacional, social e político. (ZILBERMAN; SILVA, 1991, p. 115)

Lajolo (1982, p. 112-113) reitera que a leitura também "pode se apresentar na condição de um instrumento de conscientização" e que se "relaciona ativamente com a produção cultural, 
isto é, com os objetos e atitudes em que se depositam as manifestações da linguagem, sejam estas gestuais, visuais ou verbais (oral, escrita, mista, audiovisual)". Zilberman (2008, p. 18) reforça que a literatura "[...] colabora para o fortalecimento do imaginário de uma pessoa, e é com a imaginação que solucionamos problemas".

No que tange as limitações ou desvantagens do processo de escolarização da Literatura Infantil pontuamos que a depender das estratégias pedagógicas é possível: (i) limitar o repertorio linguístico da criança, seja por meio de obras repetidas ao longo dos anos ou escolhas literárias inadequadas a faixa etária e (ii) provocar desinteresse pelo hábito de ler e até mesmo perder um leitor ativo. Prova disso, os estudos de Soares (2006) diagnosticaram como atividade educativa inadequada: 1) seleção de obras repetidas, apresentação fragmentada de textos; 2) adaptação infantilizada da obra quando da transferência de seu suporte original para o livro didático; 3) alteração de gênero: de fábula para histórias em quadrinhos, por exemplo, e por último 4) constata que o ensino tem meramente uma função pragmática e pretextos a gramáticas ou outros conteúdos. Em consonância, Lajolo (1984, p. 52) adverte que

o texto não é pretexto para nada. Ou melhor, não deve ser. Um texto existe apenas na medida em que se constitui ponto de encontro entre dois sujeitos: o que o escreve e o que o lê; escritor e leitor, reunidos pelo ato radicalmente solitário da leitura, contrapartida do igualmente solitário ato de escritura. (LAJOLO, 1984, p. 52)

Vale destacar, então, que cada gênero tem suas características específicas, alguns com sonoridade, ritmo, musicalidade, linguagem verbal ou não-verbal. Por isso o aspecto composicional, estético e discursivo deve ser valorizado e diferenciado, visto que os livros se transformam em memórias afetivas. Para Zilberman (2005, p. 9), “[...] livros lidos na infância permanecem na memória do adolescente e do adulto, responsáveis que foram por bons momentos aos quais as pessoas não cansam de regressar".

De modo geral, conforme Aguiar (2004), a formação do leitor passa pela fase da préleitura, leitura compreensiva, leitura interpretativa, iniciação à leitura crítica e leitura crítica. Na primeira infância (0 a 5 anos) "iniciam o processo realizando pré-leituras, por ainda não serem alfabetizadas" e nesta fase que a criança desenvolve "as habilidades e as capacidades que a tornarão aptas para o aprendizado da leitura, por meio da construção de símbolos, desenvolvimento da linguagem oral e percepção, a criança conseguirá estabelecer relações entre as imagens e as palavras". (AGUIAR, 2004, p. 22). A autora acrescenta que os interesses nessa fase são mais voltados "para histórias curtas e rimas, em livros com muitas gravuras e pouco texto escrito, que permitem a descoberta do sentido muito mais através da linguagem visual do que da verbal”. (AGUIAR, 2004, p. 25). 
Já o nível de leitura compreensiva é voltado para a fase de alfabetização ( $1^{\circ}$ e $2^{\circ}$ ano), codificação e decodificação do sistema alfabético, e o da leitura interpretativa, abrangendo crianças de $3^{\circ}$ ao $5^{\circ}$ ano. $\mathrm{O}$ da iniciação à leitura crítica, envolvendo jovens por volta do $6^{\circ}$ e $7^{\circ}$ ano, e, o da leitura crítica, compreendendo alunos dos anos finais do ensino fundamental e Ensino Médio. Percebemos, desse modo, que a escolarização sistematiza os saberes na formação do leitor-literário e que a função pedagógica do ato de ler no contexto infantil é constituída de diálogos afetivos, por histórias que contribui para o desenvolvimento integral da criança e que a Literatura Infantil é uma ótima aliada na formação do leitor.

\section{Os critérios pedagógicos da BNCC: a (não) presença do ensino da literatura infantil}

Tendo uma visão panorâmica da implementação da BNCC no país, compreende-se que esse documento foi elaborado para unificar o modo como vem sendo objetivado o ensino básico, como unidades temáticas e competências para cada etapa. Vale apontar que o capítulo protagoniza apenas a organização curricular e as orientações voltadas para o ensino de Literatura, anos iniciais, e consequentemente Língua Portuguesa. Não navegamos pelos mares históricos, estrutura e distribuição dos outros componentes curriculares. Por conseguinte, conceitua-se a Base como um documento de

caráter normativo que define o conjunto orgânico e progressivo de aprendizagens essenciais que todos os alunos devem desenvolver ao longo das etapas e modalidades da Educação Básica, de modo a que tenham assegurados seus direitos de aprendizagem e desenvolvimento, em conformidade com o que preceitua o Plano Nacional de Educação (PNE). (BRASIL, 2018, p. 9).

Além disso, este documento foi elaborado exclusivamente à educação escolar, tal como define o $\S 1^{\circ}$ do Artigo $1^{\circ}$ da Lei de Diretrizes e Bases da Educação Nacional (LDB, Lei $n^{\circ}$ 9.394/1996) ${ }^{1}$, e está “orientado pelos princípios éticos, políticos e estéticos que visam à formação humana integral e à construção de uma sociedade justa, democrática e inclusiva, como fundamentado nas Diretrizes Curriculares Nacionais da Educação Básica (DCN)" (BRASIL, 2018, p. 9). 
Ao longo do ensino fundamental são apresentadas $\mathrm{dez}^{6}$ competências $^{7}$ gerais (pessoais/sociais; cognitivas e comunicativas), que consubstanciam, no âmbito pedagógico, os direitos de aprendizagem, os eixos estruturais dos componentes curriculares, unidades temáticas, objeto de conhecimento, competências especificas e desenvolvimento das habilidades. O Quadro 1 demonstra a divisão da base.

Quadro 1: Organização estrutural curricular e as competências gerais

\begin{tabular}{|c|c|c|c|}
\hline \multicolumn{2}{|c|}{ Educação infantil } & \multicolumn{2}{|c|}{ Ensino Fundamental } \\
\hline \multirow{3}{*}{$\begin{array}{c}\text { Direitos de } \\
\text { aprendizagem }\end{array}$} & \multirow{3}{*}{$\begin{array}{c}\text { Conviver } \\
\text { Brincar } \\
\text { Participar } \\
\text { Explorar } \\
\text { Expressar-se } \\
\text { Conhecer-se }\end{array}$} & $\begin{array}{l}\text { Anos iniciais } \\
\left(1^{\mathrm{a}} \text { ao } 5^{\mathrm{o}} \text { ano }\right)\end{array}$ & $\begin{array}{l}\text { Anos finais } \\
\left(6^{\circ} \text { ao } 9^{\circ} \text { ano }\right)\end{array}$ \\
\hline & & \multicolumn{2}{|c|}{ Áreas do conhecimento } \\
\hline & & \multicolumn{2}{|c|}{ Componentes curriculares } \\
\hline \multirow{6}{*}{$\begin{array}{l}\text { Campos de } \\
\text { experiência }\end{array}$} & \multirow{6}{*}{$\begin{array}{c}\text { O Eu, o outro e o nós } \\
\text { Corpo, gesto e movimentos } \\
\text { Traços, som, cores e } \\
\text { formas } \\
\text { Escuta, fala, pensamento e } \\
\text { imaginação } \\
\text { Espaços, tempos, } \\
\text { quantidades, relações e } \\
\text { transformações. }\end{array}$} & \multirow{4}{*}{ Linguagens } & Língua portuguesa \\
\hline & & & Arte \\
\hline & & & Educação física \\
\hline & & & Língua Inglesa \\
\hline & & Matemática & Matemática \\
\hline & & $\begin{array}{c}\text { Ciências da } \\
\text { natureza }\end{array}$ & Ciências \\
\hline \multirow{3}{*}{\multicolumn{2}{|c|}{ Objetos de aprendizagem e desenvolvimento }} & Ciências humanas & Geografia \\
\hline & & & História \\
\hline & & Ensino religioso & Ensino religioso \\
\hline
\end{tabular}

Como podemos observar a área de linguagens abrange mais componentes Curriculares e acaba tendo um diferencial dos outros componentes. A Língua Portuguesa é o único componente composto por eixos e campos de atuação, os outros é estruturado apenas por unidade temática, conforme o Quadro 2 destaca. Nessa área a Base prevê "a contemplação de uma formação plural e integral”, bem como relações pessoais e institucionais e a participação na vida em sociedade se dão pelas práticas de linguagem.

\footnotetext{
6 1- Conhecimento. 2 - Pensamento Científico, crítico e criativo. 3- Produções artísticas. 4- Comunicação. 5Cultura Digital. 6- Autogestão. 7- Argumentação. 8- Autoconhecimento e autocuidado. 9- Empatia e cooperação. 10- Autonomia.

7 “definida como a mobilização de conhecimentos (conceitos e procedimentos), habilidades (práticas, cognitivas e socioemocionais), atitudes e valores para resolver demandas complexas da vida cotidiana, do pleno exercício da cidadania e do mundo do trabalho". (BRASIL, 2018, p. 10).
} 
É por meio dessas práticas que "os sujeitos (inter) agem no mundo e constroem significados coletivos. As práticas de linguagem permitem a construção de referências e entendimentos comuns para a vida em sociedade e abrem possibilidades de expandir o mundo em que se vive, ampliando os modos de atuação e de relacionar-se" (BRASIL, 2018, p.86). Para fins de exemplificação, o Quadro 2 demonstra a organização dos componentes curriculares voltados para os anos iniciais.

Quadro 2: Organização dos componentes Curriculares anos iniciais

\begin{tabular}{|c|c|c|c|c|c|c|c|}
\hline \multicolumn{2}{|c|}{ Componente curricular } & \multicolumn{4}{|c|}{ Eixo } & \multicolumn{2}{|c|}{ Campo atuação } \\
\hline \multirow{4}{*}{\multicolumn{2}{|c|}{ Língua Portuguesa }} & \multirow{2}{*}{\multicolumn{4}{|c|}{$\begin{array}{c}\text { Leitura } \\
\text { Oralidade }\end{array}$}} & \multicolumn{2}{|c|}{ Vida cotidiana } \\
\hline & & & & & & \multirow{2}{*}{\multicolumn{2}{|c|}{$\begin{array}{c}\text { Vida pública } \\
\text { Práticas de estudo e pesquisa }\end{array}$}} \\
\hline & & \multicolumn{4}{|c|}{ Prod. de textos } & & \\
\hline & & \multicolumn{4}{|c|}{ Análise linguística / Semiótica } & \multicolumn{2}{|c|}{ Artístico-literário } \\
\hline $\begin{array}{l}\text { Componente } \\
\text { curricular }\end{array}$ & \multicolumn{3}{|c|}{ Unidade Temática } & \multicolumn{3}{|c|}{ Componente curricular } & Unidade Temática \\
\hline \multirow{4}{*}{ Matemática } & \multicolumn{3}{|c|}{ Números } & \multirow{4}{*}{\multicolumn{2}{|c|}{ Art }} & & Artes visuais \\
\hline & \multirow{2}{*}{\multicolumn{3}{|c|}{$\begin{array}{c}\text { Geometria } \\
\text { Álgebra }\end{array}$}} & & & & Dança \\
\hline & & & & & & & Música \\
\hline & \multicolumn{3}{|c|}{$\begin{array}{c}\text { Grandezas e medidas } \\
\text { Probabilidade e estatistica }\end{array}$} & & & & Teatro \\
\hline $\begin{array}{l}\text { Componente } \\
\text { curricular }\end{array}$ & \multicolumn{3}{|c|}{ Unidade Temática } & \multicolumn{3}{|c|}{ Componente curricular } & Unidade Temática \\
\hline \multirow{5}{*}{$\begin{array}{l}\text { Educação } \\
\text { Física }\end{array}$} & \multicolumn{3}{|c|}{ Brincadeiras e jogos } & \multirow{5}{*}{\multicolumn{3}{|c|}{ Ciências }} & Matéria e energia \\
\hline & \multicolumn{3}{|c|}{ Esportes } & & & & Vida e evoluçăo \\
\hline & & ticas & & & & & \\
\hline & \multirow{2}{*}{\multicolumn{3}{|c|}{$\frac{\text { Danças }}{\text { Lutas }-3^{\circ} \text { ao } 5^{\circ} \text { ano }}$}} & & & & Terra e universo \\
\hline & & & & & & & \\
\hline $\begin{array}{l}\text { Componente } \\
\text { curricular }\end{array}$ & \multicolumn{2}{|c|}{ Unidade Temática } & \multicolumn{2}{|c|}{$\begin{array}{l}\text { Componente } \\
\text { curricular }\end{array}$} & Ano & \multicolumn{2}{|c|}{ Unidade Temática } \\
\hline \multirow{5}{*}{ Geografia } & \multicolumn{2}{|c|}{$\begin{array}{c}\text { O sujeito e seu lugar } \\
\text { no mundo }\end{array}$} & \multirow{5}{*}{\multicolumn{2}{|c|}{$\begin{array}{c}\text { Ensino } \\
\text { Religioso }\end{array}$}} & $\begin{array}{c}1^{\circ}, 2^{\circ} \\
\text { e } 3^{\circ}\end{array}$ & \multirow{2}{*}{\multicolumn{2}{|c|}{$\begin{array}{l}\text { Identidades e alteridades } \\
\text { Manifestaçőes religiosas }\end{array}$}} \\
\hline & Conexö & calas & & & & & \\
\hline & Mundo & alho & & & $\begin{array}{c}4^{\circ} \\
\text { ano }\end{array}$ & $\begin{array}{r}\mathrm{Ma} \\
\text { Crenças } \mathrm{r}\end{array}$ & $\begin{array}{l}\text { ações religiosas } \\
\text { sas e filosofias de vida }\end{array}$ \\
\hline & $\begin{array}{r}\text { For } \\
\text { repres } \\
\text { pensame }\end{array}$ & o e & & & $\begin{array}{c}5^{\circ} \\
\text { ano }\end{array}$ & Crenças r & sas e filosofias de vida \\
\hline & $\begin{array}{l}\text { Natureza } \\
\text { qualid }\end{array}$ & $\begin{array}{l}\text { ntes e } \\
\text { rida }\end{array}$ & & & & & \\
\hline
\end{tabular}

Fonte: Autora (2019)

Percebe-se, desse modo, que a presença da literatura é vista como um campo de atuação, uma prática de linguagem sutilmente entre os eixos, e nomeada como uma produção artísticaliterária. Não se fala especificamente em ensino de Literatura, mas sim em manifestações e produções artísticas- literárias. Ao longo do documento é perceptível as práticas literárias mais no eixo da leitura, mas recomenda-se uma articulação de gêneros literários com os outros eixos e aponta o letramento literário como parte do processo de alfabetização, do leitor-literário infantil. 
Nesse aspecto, o letramento literário é entendido como "o processo de apropriação da literatura como linguagem que oferece uma experiência estética, bem como a ampliação gradativa das referências culturais compartilhadas nas comunidades de leitores que se constituem na escola”. (BRASIL, 2018, p. 97). O documento acrescenta que pela literatura, "constituem-se subjetividades, expressam-se sentimentos, desejos, emoções, de um modo particular, com uso diversificado de recursos expressivos" (BRASIL, 2016 p. 98).

O documento posiciona uma visão ambígua, de um lado demonstra uma valorização da leitura literária, da educação literária, em seus diversos gêneros, e que é essencial para a formação do leitor, mas de outro modo aborda a literatura subcategorizada, ramificada entre os eixos como pré-texto, um ponto inicial para abordar qualquer temática ou aspectos gramaticais, ou para outras formas de construção de conhecimento ou como uma estratégia pedagógica de um ensino contextualizado, significativo, por aproximar das práticas sociais dos educandos.

Na BNCC “propõe-se uma leitura literária que seja capaz de resgatar a historicidade do texto: a produção, a circulação e a recepção da obra literária, em um entrecruzamento de diálogos (entre obras, entre leitores, entre tempos históricos). (BRASIL, 2018, p. 508). Confirma, então, a ideia de que é importante a ligação de aspectos estéticos da obra literária com o seu caráter histórico, tendo como foco a formação do leitor de modo espontâneo e natural.

Apesar das contrariedades, o documento, de modo geral, frisa um leitor infantil ativo e que a leitura literária deve fazer parte do processo de escolarização e defende o ensino da literatura como ação pedagógica, educativa, e como recurso linguístico que vá além dos recursos estéticos. Consequentemente, a BNCC por integrar a política nacional da Educação Básica contribuiu para o alinhamento de outras políticas e ações, em âmbito federal, estadual e municipal, referentes às escolhas literárias, formação de professores, à avaliação, à elaboração de conteúdos educacionais e aos critérios avaliativos de aprovação e reprovação dos LT.

\section{Considerações finais}

Todo o constructo da análise levou a refletir sobre tanto os fatores que inferem no processo de formação do leitor e a Literatura Infantil como prática educativa. Assim, nota-se contrariedades da BNCC, visto que apesar de enfatizar sua relevância, em suas diversidades estéticas e linguísticas, é abordada de forma secundária entre os eixos de ensino. O documento analisado nos traz um embate que de um lado temos a obrigatoriedade da leitura literária nas escolas, a sistematização do ensino da literatura, na qual o aluno terá que ler especificamente 
apenas as obras disponibilizadas pela escola e de outro as obras vistas como uma forma de promoção e acesso à leitura e, na maioria dos contextos educacionais, o paradidático é o único recurso literário que o leitor terá acesso à leitura (BRASIL, 2017).

Vale pontuar, que o planejamento pedagógico pode fazer toda diferença no ato de ler de forma escolarizada. Desse modo, as leituras não podem ser apenas de cunho avaliativo, normativo, mas sim formativo. Acreditamos que uma escolarização inadequada na infância faz o que se perda um leitor em potencial na vida adulta. Um dos aspectos necessário nas práticas educativas é entender que o LT tem funções sociais e que a Literatura Infantil é mergulhada, não só de fantasias, mas de saberes que desenvolve o cognitivo, de modo lúdico e críticoreflexivo.

Paradigmas, devem ser rompidos nas práticas literárias. Por fim, a literatura deve fazer parte do processo de escolarização dos educandos e concluímos nos apropriando das palavras de Lajolo (1988, p. 43) ao alertar que é um engano achar que o caráter humanizante e formador da literatura "vem da natureza ou quantidade de informações que ela propicia ao leitor. Literatura não transmite nada. Cria. Dá existência plena ao que, sem ela, ficaria no caos do inomeado e, consequentemente, do não existente para cada um".

\section{Referências}

BRASIL. Ministério da Educação. Base nacional comum curricular. MEC. Brasília, DF, 2018.

BRITTO, L.P.L. Letramento e Alfabetização: implicações para a educação infantil. In: COLOMER, Teresa. A formação do leitor literário: narrativa infantil e juvenil atual/ Teresa Colomer; tradução Laura Sandroni. - São Paulo: Global, 2003.

FARIA, A.L.G \& MELLO, S.A. (orgs.) O Mundo da escrita no universo da pequena infância. Campinas, SP: Autores Associados, 2005.

GOULART, C. Educação Infantil: "nós já somos leitores e produtores de textos". Presença Pedagógica. v.11, n. 63, p. 16-21, Mai./Jun. 2005.

LAJOLO, Marisa Philbert. Usos e abusos da literatura na escola: Bilac e a literatura escolar na república velha / Marisa Lajolo. Rio de Janeiro: GLOBO, 1982.

QUEIROZ, Vera. Crítica literária e estratégias de gênero. Niterói: EDUFF, 1997.

LAJOLO, Marisa. O texto não é pretexto. In. Leitura em crise na escola: as alternativas do professor $3^{\mathrm{a}}$ ed. Porto Alegre: Mercado Aberto, 1984.

TODOROV, Tzvetan. A literatura em perigo. Difel, 2009. 
RAMOS, Anna Claudia. Nos bastidores do imaginário: criação e literatura infantil e juvenil. São Paulo: DCL, 2006.

SOARES, Magda Becker. Letramento e escolarização. In: RIBEIRO, Vera Masagão (Org.). Letramento no Brasil: reflexões a partir do INAF 2001. 2. ed. São Paulo: Global, 2004a.

SOARES, Magda Becker. A escolarização da Literatura Infantil e Juvenil. In: de EVANGELISTA, Aracy, et al. (Orgs.). A escolarização da literatura: o jogo do livro infantil e juvenil. Belo Horizonte: Autêntica, 1999.

SOARES, Magda. A escolarização da literatura infanto juvenil. In: EVANGELISTA, A. A. M.; BRANDÃO, H. M. B.; MACHADO, M. Z. V. (orgs). Escolarização da leitura literária. 2. ed. Belo Horizonte: Autêntica, 2001.

SCHMIDT, Rita Teresinha. Repensando a cultura, a literatura e o espaço da autoria feminina. In: NAVARRO, Márcia Hoppe (Org.). Rompendo o silêncio: gênero e literatura na América Latina. Porto Alegre: Editora da UFRGS, 1995.

ZILBERMAN, Regina. Literatura e pedagogia: ponto e contraponto. Porto Alegre: Mercado Aberto, 1990. 